\title{
Right ventricular dysfunction in patients with obstructive sleep apnoea syndrome
}

\author{
B.M. Sanner*, M. Konermann**, A. Sturm*, H.J. Müller+, W. Zidek*
}

Right ventricular dysfunction in patients with obstructive sleep apnoea syndrome. B.M. Sanner, M. Konermann, A. Sturm, H.J. Müller, W. Zidek. @ ERS Journals Ltd 1997.

ABSTRACT: There is conclusive evidence that obstructive sleep apnoea syndrome (OSAS) influences right heart haemodynamics and can also induce pulmonary hypertension. It is not known, however, whether right ventricular dysfunction can occur in patients with OSAS in the absence of lung disease.

We studied 107 patients (94 males, 13 females, mean age 55 \pm 11 yrs) with polysomnographically verified OSAS in whom clinically significant lung disease was excluded. Right ventricular ejection fraction (RVEF) was determined by radionuclide ventriculography. In addition, pulmonary function tests, arterial blood gas analysis and right heart catheterization were performed.

RVEF was impaired in 19 patients $(18 \%)$. Eighteen $(95 \%)$ had signs or symptoms consistent with mild right ventricular failure. Patients with or without impaired RVEF did not differ with respect to body mass index, age or lung function. Stepwise multiple logistic regression analysis revealed that RVEF was significantly associated with the apnoea/hypopnoea index $(r=-0.68 ; p=0.0009)$ and the extent of nocturnal oxyhaemoglobin saturation $(r=0.42 ; p=0.035)$, but not with age, body mass index, blood gas analysis, gender, lung function, pulmonary artery pressure and left ventricular ejection fraction.

We conclude that in patients with otherwise unexplained right ventricular failure, obstructive sleep apnoea syndrome may underlie the right ventricular dysfunction.

Eur Respir J 1997; 10: 2079-2083.
*Dept of Medicine I, **Dept of Medicine II, +Dept of Radiology, Ruhr University Bochum, Marienhospital Herne, Germany.

Correspondence: B.M. Sanner

Dept of Medicine I

Ruhr University Bochum

Marienhospital

Hölkeskampring 40

44625 Herne

Germany

Keywords: Obstructive sleep apnoea syndrome

radionuclide ventriculography

right ventricular ejection fraction

Received: October 211996

Accepted after revision May 271997
Obstructive sleep apnoea syndrome (OSAS) is a common condition characterized by repeated pauses (apnoeas) or reductions (hypopnoeas) in breathing during sleep [1]. It is caused by a complete or partial upper airway obstruction, which leads to increasing pleural pressure swings, decreases in oxyhaemoglobin saturation and subsequent arousal from sleep, whereupon airway patency is restored and airflow resumes.

These mechanisms seem to be responsible for a series of secondary physiological events, which in turn give rise to the clinical complication of the syndrome and probably associated cardiovascular disease [2, 3].

While episodic nocturnal pulmonary hypertension in OSAS is well described [4,5], the consequences of OSAS with respect to the function of the right ventricle are less well studied [6-9]. Right ventricular dysfunction occurring in patients with OSAS has generally been attributed to concomitant chronic obstructive lung disease, hypercapnia, or at least mild hypoxia [8, 10-12]. As yet, no direct association between OSAS and right ventricular dysfunction is known. To examine this question, the prevalence of right ventricular dysfunction and parameters possibly influencing right ventricular function were studied in a group of OSAS patients in whom an intrinsic pulmonary disorder was excluded.

\begin{abstract}
Methods
Study design

One hundred and seven consecutive patients (94 males, 13 females) referred to our sleep laboratory for snoring, suspected OSAS, or excessive daytime sleepiness with a mean age of $55 \pm 11$ yrs (range 28-74) and a mean body mass index (BMI) of 31-52 $\mathrm{kg} \cdot \mathrm{m}^{-2}$ (range $22.5-42.8$ ) were prospectively studied. The enrolment criterion was a polysomnographically verified OSAS (apnoea/hypopnoea index $(\mathrm{AHI})>10$ events $\cdot \mathrm{h}^{-1}$ associated with typical clinical features). All patients were in regular sinus rhythm. Seventy six patients $(71 \%)$ had a known or newly diagnosed arterial hypertension and 21 patients (20\%) had diabetes mellitus. Forty eight of the patients with arterial hypertension were on regular antihypertensive treatment, and 18 of the patients with diabetes mellitus were treated with sulphonylureas or insulin.

Patients with clinical, laboratory or lung function evidence of chronic lung disease, evidence of left ventricular failure, or with hypoventilation from central nervous disorders were excluded from the study. Left ventricular failure was defined radiographically by left
\end{abstract}


ventricular enlargement or evidence of pulmonary venous hypertension.

The study was approved by the Ethics Committee of the Ruhr University, Bochum, Germany. Following their advice, no control group was included in the study in order to prevent unnecessary radionuclide exposure. All patients gave their informed consent.

Polysomnography (Somnostar 4100, SensorMedics Co., Yorba Linda, CA, USA) was performed according to internationally approved methods [13]. It consisted of continuous polygraphic recording from surface leads for electroencephalography, electro-oculography, electromyography, and electrocardiography, and from noninvasive sensors for nasal and oral airflow, tracheal sounds (microphone), thoracic and abdominal respiratory effort (inductance plethysmography), and oxyhaemoglobin level (Sat-Trak ${ }^{\mathrm{TM}}$, finger-pulse oximeter, SensorMedics Co., Yorba Linda, CA, USA). The transducers and lead wires permitted normal positional changes during sleep. Bedtime and awakening time were at each subject's discretion. Polysomnography was terminated after final waking.

Polysomnography records were scored in 30 s periods for sleep, breathing and oxygenation. According to the commonly used clinical criterion, a breathing event during objectively measured sleep was defined as abnormal if either a complete cessation of airflow lasting $10 \mathrm{~s}$ or more took place (apnoea) or a reduction in respiratory airflow accompanied by a decrease of $4 \%$ or more in oxyhaemoglobin saturation could be discerned (hypopnoea). The average number of episodes of apnoea and hypopnoea per hour of sleep (AHI) was calculated. Sleep was staged manually using the methods of ReChTSCHAFFEN and KaLEs [14].

The morning after the all-night polysomnogram, right and left ventricular ejection fractions were determined by radionuclide ventriculography, using the equilibrium method with technetium-99m attached to red blood cells as the radioactive intravascular indicator. Counts were recorded with a scintillation camera (Gamma-Diagnostik Tomo, Phillips, Germany) in at least two views from approximately 1,100 cardiac cycles following uniform distribution of radiotracer throughout the blood pool. The examination was performed during the day, at rest, and at least $12 \mathrm{~h}$ after any medication. Since there may be difficulties in the separation of the right ventricle from the left ventricle and pulmonary artery, ejection fractions were calculated manually by a nuclear medicine radiologist, who was unaware of the severity of OSAS. Right ventricular ejection fraction (RVEF) $<45 \%$ was defined as abnormal [15].

In order to determine the factors that might influence right ventricular function, the following examinations were performed in all patients the morning after the polysomnographical study: 1) Pulmonary function test (bodyplethysmography) (Bodyscreen II, Erich Jaeger GmbH and Co. KG, Hoechberg, Germany). None of the patients received medication. Forced vital capacity (VC), residual volume, total lung capacity, forced expiratory volume in one second, maximal midexpiratory flow, and airway resistance were determined; 2) Arterial blood gas analysis (Stat Profile, Nova Biomedical, Roedermark, Germany). Arterial oxygen $\left(\mathrm{Pa}, \mathrm{O}_{2}\right)$ and carbon dioxide tensions $\left(\mathrm{Pa}, \mathrm{CO}_{2}\right)$ were calculated; 3$)$ Right heart catheterization by the arm approach (French size no. 6, Vygon, France; Recor 287, Siemens, Germany) was performed 2 days after polysomnography. The haemodynamic measurements were carried out with a bicycle ergometer in the supine position during the day, free of any medication (no drugs were administered on the same morning), and at rest and during exercise with a load of $100 \mathrm{~W}$, starting with $25 \mathrm{~W}$ and increasing in 25 $\mathrm{W}$ steps every $4 \mathrm{~min}$. The mean pulmonary artery pressure $(P$ pa $)$ and pulmonary capillary wedge pressure $\left(P_{\text {cwp }}\right)$ were recorded. Abnormal $P$ pa were defined as $\geq 20 \mathrm{mmHg}$ at rest and $\geq 30 \mathrm{mmHg}$ during exercise with a load of $100 \mathrm{~W}$.

\section{Statistical analysis}

Results are presented as mean \pm SD. All reported pvalues are two-tailed. Statistical analyses were performed with Statistical Package for the Social Sciences (SPSS) for Windows software (SPSS, Chicago, IL, USA) [16]. Intergroup differences were analysed with nonparametric tests (Wilcoxon, Mann-Whitney). To determine the independent association of the severity of obstructive sleep apnoea with RVEF in the presence of other significant risk factors, stepwise multiple logistic regression analysis was performed. The multivariate statistical model was built in steps and was designed to select only factors correlated with RVEF at a level of significance less than or equal to 0.05 for the final multiple regression model. Possible risk factors, including age, gender, BMI, parameters of lung function, $P \mathrm{a}, \mathrm{O}_{2}$ and $\mathrm{Pa}, \mathrm{CO}_{2}$, $\bar{P}$ pa and left ventricular ejection fraction (LVEF) were allowed to compete. Gender was entered into the model as a categorical variable.

\section{Results}

In 19 of 107 patients (18\%; all males), right ventricular dysfunction, as defined by radionuclide ventriculography, was observed. To determine which parameters brought about the occurrence of right ventricular dysfunction in patients with OSAS, the patients with and without right ventricular dysfunction were compared. Table 1 shows the clinical signs and symptoms consistent with right ventricular dysfunction in these patients. These symptoms were exclusively based on the subjective complaints of the patients.

Table 1. - Clinical signs and symptoms consistent with right ventricular dysfunction in patients with and without right ventricular (RV) dysfunction, as defined by radionuclide ventriculography

\begin{tabular}{lccc}
\hline & $\begin{array}{c}\mathrm{RV} \\
\text { dysfunction } \\
(\mathrm{n}=19)\end{array}$ & $\begin{array}{c}\text { Normal RV } \\
\text { function } \\
(\mathrm{n}=88)\end{array}$ & $\begin{array}{c}\text { Statistical } \\
\text { significance }\end{array}$ \\
\hline $\begin{array}{l}\text { Symptoms } \\
\text { Dyspnoea on exertion }\end{array}$ & $\begin{array}{l}7(37) \\
1(5)\end{array}$ & $\begin{array}{c}9(10) \\
5(6)\end{array}$ & $\begin{array}{c}\mathrm{p}<0.005 \\
\mathrm{NS}\end{array}$ \\
$\begin{array}{l}\text { Oedema } \\
\text { Nocturia }\end{array}$ & $17(89)$ & $48(55)$ & $\mathrm{p}<0.005$ \\
$\begin{array}{l}\text { Clinical signs } \\
\text { Oedema }\end{array}$ & $3(16)$ & $5(6)$ & $\mathrm{NS}$ \\
$\begin{array}{l}\text { No clinical signs or } \\
\text { symptoms }\end{array}$ & $1(5)$ & $36(41)$ & $\mathrm{p}<0.005$ \\
\hline
\end{tabular}

Values are absolute numbers, and percentage in parenthesis. NS: nonsignificant. 
Table 2. - Anthropometric and polysomnographic data of the patients with and without right ventricular dysfunction

\begin{tabular}{lcc}
\hline & $\begin{array}{c}\text { Right ventricular } \\
\text { dysfunction } \\
(\mathrm{n}=19)\end{array}$ & $\begin{array}{c}\text { Normal right } \\
\text { ventricular function } \\
(\mathrm{n}=88)\end{array}$ \\
\hline Age yrs & $56 \pm 10$ & $55 \pm 11$ \\
Body mass index, $\mathrm{kg} \cdot \mathrm{m}-2 *$ & $30 \pm 6$ & $32 \pm 5$ \\
Total sleep time min & $316 \pm 89$ & $320 \pm 64$ \\
Stage wake \% & $18 \pm 15$ & $18 \pm 14$ \\
Sleep stage 1\% & $7 \pm 8$ & $8 \pm 10$ \\
Sleep stage 2\% & $49 \pm 12$ & $52 \pm 16$ \\
Sleep stage 3\% & $7 \pm 5$ & $8 \pm 7$ \\
Sleep stage 4\% & $4 \pm 7$ & $2 \pm 4$ \\
Sleep stage REM $\%$ & $15 \pm 10$ & $11 \pm 8$ \\
AHI Events $\mathrm{h}-1$ & $42 \pm 22$ & $37 \pm 22$ \\
$t>90 \%$ \% & $70 \pm 36$ & $77 \pm 29$ \\
\hline
\end{tabular}

Values are presented as mean \pm SD. There were no significant differences between groups. $t>90 \%$ : time during sleep with an oxygen saturation $>90 \%$; REM: rapid eye movement; AHI: apnoea/hypopnoea index. *: the weight in kilograms divided by the square of the height in meters.

Oedema were noted in patients with and without right ventricular failure. In the five patients with normal right ventricular function, the oedema may have been caused by primary varicose veins in one case, antihypertensive therapy with nifedipine in two cases and moderate renal failure in two cases. One of the patients with right ventricular dysfunction was receiving antihypertensive therapy with nifedipine; none of the patients had chronic renal failure.

Patients with and without right ventricular failure did not differ with respect to age, BMI, sleep structure, or severity of OSAS as defined by the AHI or the time durTable 3. - Respiratory function, right heart haemodynamics, and left ventricular ejection fraction in patients with and without right ventricular dysfunction

\begin{tabular}{|c|c|c|}
\hline & $\begin{array}{l}\text { Right ventricular } \\
\text { dysfunction } \\
(\mathrm{n}=19)\end{array}$ & $\begin{array}{l}\text { Normal right } \\
\text { ventricular function } \\
(\mathrm{n}=88)\end{array}$ \\
\hline FVC $\%$ pred & $94 \pm 9$ & $94 \pm 13$ \\
\hline RV \% pred & $101 \pm 19$ & $110 \pm 31$ \\
\hline TLC $\%$ pred & $94 \pm 7$ & $97 \pm 13$ \\
\hline FEV1 $\%$ pred & $86 \pm 25$ & $89 \pm 20$ \\
\hline FEV1/FVC $\%$ pred & $96 \pm 16$ & $94 \pm 21$ \\
\hline MMEF \% pred & $76 \pm 33$ & $83 \pm 33$ \\
\hline$R$ aw $\%$ pred & $85 \pm 21$ & $84 \pm 42$ \\
\hline $\mathrm{Pa}_{\mathrm{a}, \mathrm{O}_{2}} \mathrm{mmHg}$ & $84 \pm 17$ & $84 \pm 12$ \\
\hline $\mathrm{Pa}, \mathrm{CO}_{2} \mathrm{mmHg}$ & $36 \pm 4$ & $36 \pm 4$ \\
\hline$P$ a,rest $\mathrm{mmHg}$ & $16 \pm 4$ & $15 \pm 4$ \\
\hline$P \mathrm{a}, 100 \mathrm{w} \mathrm{mmHg}$ & $32 \pm 8$ & $33 \pm 10$ \\
\hline$P$ pcw,rest $\mathrm{mmHg}$ & $8 \pm 3$ & $8 \pm 3$ \\
\hline$P$ pcw, $100 \mathrm{w} \mathrm{mmHg}$ & $17 \pm 7$ & $17 \pm 8$ \\
\hline LVEF \% & $56 \pm 10$ & $59 \pm 9$ \\
\hline
\end{tabular}

There were no significant differences between groups. FVC: forced vital capacity; \% pred: percentage of normal predicted value; RV: residual volume; TLC: total lung capacity; FEV1: forced expiratory volume in one second; MMEF: maximal midexpiratory flow; Raw: airway resistance; $P_{a}, O_{2}$ : arterial oxygen tension; $\mathrm{Pa}_{\mathrm{a}} \mathrm{CO}_{2}$ : arterial carbon dioxide tension; $P$ a,rest: pulmonary artery pressure at rest; $P \mathrm{a}, 100 \mathrm{~W}$ : pulmonary artery pressure during exercise with $100 \mathrm{~W}$; $P$ pcw,rest: pulmonary capillary wedge pressure at rest; $P_{\mathrm{pcw}, 100 \mathrm{~W}}$ pulmonary capillary wedge pressure during exercise with $100 \mathrm{~W}$; LVEF: left ventricular ejection fraction. $(1 \mathrm{mmHg}=0.133 \mathrm{kPa})$.

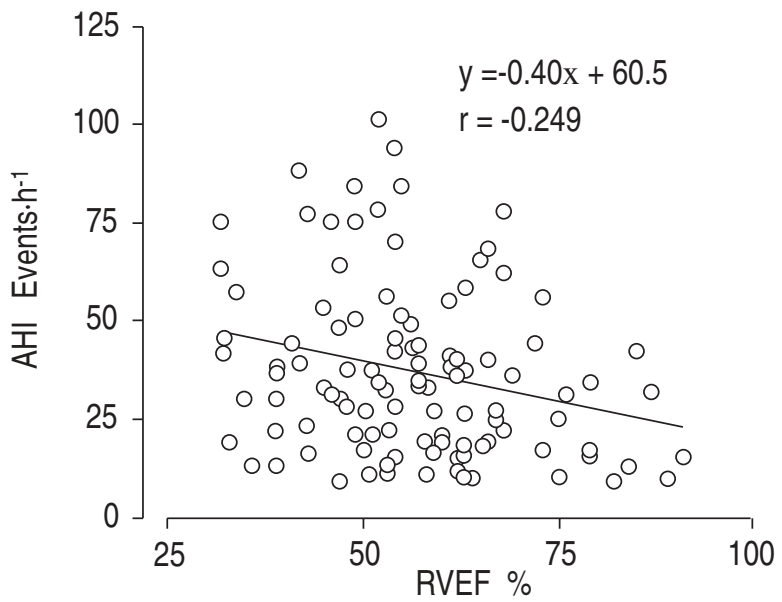

Fig. 1 - Apnoea/hypopnoea index (AHI) for all 107 patients plotted as a function of right ventricular ejection fraction (RVEF).

ing sleep with an oxygen saturation above $90 \%$ (table 2 ). There were no differences in the parameters of pulmonary function tests, $P_{\mathrm{a}}, \mathrm{O}_{2}$ and $P_{\mathrm{a}}, \mathrm{CO}_{2}, \bar{P}_{\mathrm{pa}}, P_{\mathrm{cwp}}$ at rest and during exercise, and LVEF (table 3 ). Fifty two percent of the patients with impaired right ventricular function and $48 \%$ of the patients with RVEF had coexistent pulmonary artery hypertension at rest or during exercise.

Right ventricular dysfunction was generally mild with a mean ejection fraction of $38 \pm 4 \%$ (range $32-43 \%$ ), compared to $61 \pm 11 \%$ (range $45-91 \%$ ) in patients with normal right ventricular function.

There was a significant correlation between variables indicating the severity of OSAS and RVEF. The correlation coefficient between the AHI and RVEF was r=0.249 ( $n=107, p<0.01$ ) (fig. 1), and $r=0.293(n=107$, $\mathrm{p}<0.01$ ) between the time spent at night with an oxygen saturation above $90 \%$ and RVEF (fig. 2). Table 4 shows the results of stepwise multiple logistic regression analysis performed in order to determine the independent contribution of each factor to the risk of right ventricular dysfunction. Only the two parameters indicative of the severity of OSAS, i.e. the AHI and the time during sleep with an oxyhaemoglobin saturation above $90 \%$, were significantly associated with the

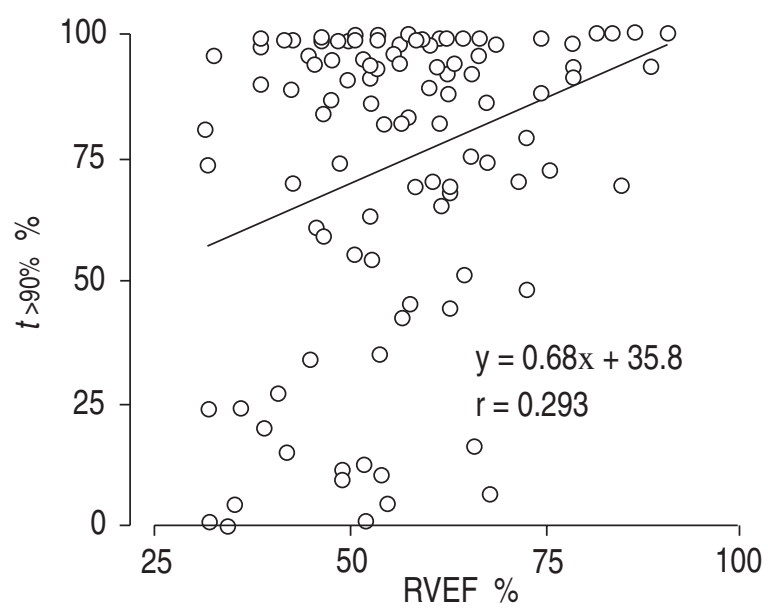

Fig. 2. - Time at night spent with an oxygen saturation above $90 \%$ $(t>90 \%)$ for all 107 patients plotted as a function of right ventricular ejection fraction (RVEF). 
Table 4. - Stepwise multiple logistic regression analysis of potential risk factors for right ventricular dysfunction in patients with OSAS

\begin{tabular}{|c|c|c|}
\hline Risk factor & $\mathrm{r}$ & $\begin{array}{l}\text { Statistical } \\
\text { significance }\end{array}$ \\
\hline \multicolumn{3}{|l|}{ Variables in the equation } \\
\hline Apneoa/hypopnoea index & -0.68 & 0.0009 \\
\hline$t>90 \%$ & 0.42 & 0.035 \\
\hline \multicolumn{3}{|l|}{ Variables not in the equation } \\
\hline Age & 0.02 & 0.87 \\
\hline Gender & 0.18 & 0.23 \\
\hline Body mass index & 0.09 & 0.53 \\
\hline FVC & 0.01 & 0.92 \\
\hline RV & 0.08 & 0.57 \\
\hline TLC & 0.05 & 0.75 \\
\hline FEV1 & 0.09 & 0.82 \\
\hline FEV1/FVC & -0.02 & 0.87 \\
\hline MMEF & -0.08 & 0.58 \\
\hline Raw & 0.18 & 0.24 \\
\hline$P \mathrm{a}, \mathrm{O}_{2}$ & -0.01 & 0.92 \\
\hline $\mathrm{Pa}, \mathrm{CO}_{2}$ & 0.03 & 0.84 \\
\hline$P$ a,rest & 0.03 & 0.85 \\
\hline$P \mathrm{a}, 100 \mathrm{~W}$ & 0.02 & 0.90 \\
\hline LVEF & 0.08 & 0.55 \\
\hline
\end{tabular}

r: multiple correlation coefficient. Age, body mass index, apnoea/hypopnoea index, $t>90 \%$, gender, parameters of lung function, blood gas analysis, pulmonary artery pressures and LVEF were allowed to compete in the model $\left(r^{2}=0.24\right)$. For definitions see legend to table 3 .

degree of right ventricular dysfunction in this model. None of the other possible risk factors tested were included in the stepwise multiple logistic regression model because the significance level exceeded 0.05 .

\section{Discussion}

The principal finding of this study is the observation of a significant association of the severity of OSAS with right ventricular dysfunction, even in the absence of lung disease. Although the impairment of RVEF was only mild, right ventricular dysfunction could be detected in as much as $18 \%$ of the study population.

In earlier studies, right ventricular dysfunction in OSAS patients was exclusively attributed to concomitant chronic pulmonary disorders [10-12]. The present study revealed an association between nocturnal oxyhaemoglobin desaturation and AHI on the one hand and impairment of RVEF on the other, independent of age, BMI, gender, blood gas analysis, LVEF, and lung function. A recently published study could also demonstrate right ventricular dysfunction in patients with OSAS and without overt pulmonary disease [8]. However, the design was different from the present study, in that NAHMias et al. [8] studied obese patients with pronounced hypercapnia, at least mild hypoxia, and reduced VC. In contrast, the patients in the present study all had a completely normal respiratory function. This strict selection of patients could render our conclusions as to the role of OSAS for right ventricular failure more valid.

What is the pathogenesis of right ventricular dysfunction associated with OSAS? Earlier studies on $\bar{P}_{\text {pa }}$ in OSAS patients suggest that haemodynamic factors may be responsible. In $20-40 \%$ of OSAS patients, $\bar{P}$ pa was found elevated [7, 17-20]. These studies showed that OSAS is related to raised $\bar{P}_{\text {pa }}$ mainly in association with pathological lung function tests or daytime blood gases. However, in these studies, right ventricular function was not assessed. The pathogenetic chain of events may, therefore, include chronic pulmonary artery hypertension inducing right ventricular hypertrophy, which in turn can lead to right ventricular failure [21, 22].

However, only $52 \%$ of our study subjects with impaired and $48 \%$ of the patients with normal RVEF had daytime pulmonary hypertension at rest or during exercise. Thus, our data do not support speculation that pulmonary hypertension is the determining cause of reduced RVEF. There must be further mechanisms responsible for the development of right ventricular dysfunction. On the one hand it can be assumed that patients with OSAS have intermittent nocturnal volume and pressure strains leading to repetitive rises in systolic and diastolic right ventricular wall tension [23], which can both trigger myocardial hypertrophy [24], but may not be disclosed in daytime measurements. On the other hand, neurohumoral mechanisms have to be considered.

It has been shown that sympathetic nerve activity increases markedly throughout the course of apnoea, reaching a peak at the onset of ventilation, followed by an abrupt drop [25]. Also, an elevated sympathetic activity could be demonstrated in awake patients with OSAS [26-28]. Since augmented sympathetic activity can have a direct trophic myocardial effect $[29,30]$, it can also result in myocardial dysfunction in the longterm [22].

In conclusion, patients with obstructive sleep apnoea syndrome have a high prevalence of right ventricular dysfunction even in the absence of associated lung disease. Both the apnoea/hypopnoea index and the extent of nocturnal oxyhaemoglobin desaturation are factors influencing the severity of right ventricular dysfunction. Our findings therefore indicate that obstructive sleep apnoea syndrome may constitute an important and independent risk factor for right ventricular dysfunction. Consequently, patients with otherwise unexplained right ventricular dysfunction should be screened for nocturnal breathing disorders.

\section{References}

1. Guilleminault C, Tilkian A, Dement WC. The sleep apnea syndromes. Annu Rev Med 1976; 27: 465-484.

2. Sanner B, Konermann M, Sturm A. Cardiac structural changes in patients with obstructive sleep apnea. Z Kardiol 1995; 84: 360-364.

3. Schäfer H, Koehler U, Hasper E, Ewig S, Lüderitz B. Sleep apnea and cardiovascular risk. Z Kardiol 1995; 84: 871-884.

4. Tilkian AG, Guilleminault C, Schroeder JS, Lehrman KL, Simmons FB, Dement W. Hemodynamics in sleepinduced apnea. Ann Intern Med 1976; 85: 714-719.

5. Podszus T, Bauer W, Mayer J, Penzel T, Peter JH, von Wichert P. Sleep apnea and pulmonary hypertension. Klin Wschr 1986; 64: 131-134.

6. Fletcher EC, Schaaf JW, Miller J, Fletcher JG. Longterm cardiopulmonary sequelae in patients with sleep apnea and chronic lung disease. Am Rev Respir Dis 1987; 135: 525-533. 
7. Kessler R, Chaouat A, Weitzenblum E, et al. Pulmonary hypertension in the obstructive sleep apnoea syndrome: prevalence, causes and therapeutic consequences. Eur Respir J 1996; 9: 787-794.

8. Nahmias J, Lao R, Karetzky M. Right ventricular dysfunction in obstructive sleep apnea: reversal with nasal continuous positive airway pressure. Eur Respir J 1996; 9: 945-951.

9. Sanner B, Konermann M, Müller HJ, Grötz J, Laschewski F, Kreuzer I. Right ventricular function in patients with obstructive sleep apnea. Wien Med Wschr 1995; 145: 518-520.

10. Weitzenblum E, Krieger J, Apprill M, et al. Daytime pulmonary hypertension in patients with obstructive sleep apnea syndrome. Am Rev Respir Dis 1988; 138: 345-349.

11. Bradley TD. Right and left ventricular functional impairment and sleep apnea. Clin Chest Med 1992; 13: 459-479.

12. Bradley TD, Rutherford R, Grossman RF, et al. Role of daytime hypoxemia in the pathogenesis of right heart failure in the obstructive sleep apnea syndrome. Am Rev Respir Dis 1985; 131: 835-839.

13. American Thoracic Society - Medical Section of the American Lung Association. Indications and standards for cardiopulmonary sleep studies. Am Rev Respir Dis 1989; 139: 559-568.

14. Rechtschaffen A, Kales A, eds. U.S. Public Health Service. A manual of standardized terminology, techniques and scoring system for sleep stages of human subjects. Washington, DC, U.S. Government Printing Office, 1968. NIH publication No. 204

15. Berger HJ, Matthay RA, Loke J, Marshall RC, Gottschalk A, Zaret BL. Assessment of cardiac performance with quantitative radionuclide angiography: right ventricular ejection fraction with reference to findings in chronic obstructive pulmonary disease. Am J Cardiol 1978; 41: 897-901.

16. Norusis MJ. Advanced statistics. Chicago, SPSS, 1988.

17. Krieger J, Sforza E, Apprill M, Lampert E, Weitzenblum E, Ratomaharo J. Pulmonary hypertension, hypoxemia, and hypercapnia in obstructive sleep apnea patients. Chest 1989; 96: 729-737.

18. Laks L, Lehrhaft B, Grunstein RR, Sullivan CE. Pulmonary hypertension in obstructive sleep apnoea. Eur Respir $J$ 1995; 8: 537-541.
19. Pulmonary Hypertension in Sleep Apnea Study Group (PHISA). Pulmonary hypertension in obstructive sleep apnea - retrospective multi-centre study. Am Rev Respir Dis 1992; 145: A865.

20. Sajkov D, Cowie RJ, Thornton AT, Espinoza HA, McEvoy RD. Pulmonary hypertension and hypoxemia in obstructive sleep apnea syndrome. Am J Respir Crit Care Med 1994; 149: 416-422.

21. Davidson WR Jr, Stauffer JL, Reeves-Hoche MK, Zwillich $\mathrm{CW}$. Cardiac sequelae of sleep-disordered breathing in obstructive sleep apnoea: new evidence for right ventricular dysfunction. Am Rev Respir Dis 1993; 47: A1015.

22. Katz AM. The cardiomyopathy of overload: an unnatural growth response in the hypertrophied heart. Ann Intern Med 1994; 121: 363-371.

23. Coccagna G, Mantovani M, Brignani F, Parchi C, Lugaresi E. Continuous recording of the pulmonary and systemic arterial pressure during sleep in syndromes of hypersomnia with periodic breathing. Bull Eur Physiopathol Respir 1972; 8: 1159-1172.

24. Anversa P, Ricci R, Olivetti G. Quantitative structural analysis of the myocardium during physiologic growth and induced cardiac hypertrophy: a review. J Am Coll Cardiol 1986; 7: 1140-1149.

25. Hedner J. Consequences of increased sympathic activity in sleep apnea. Strasbourg: 10th Congress of the European Sleep Research Society, 1990: 9.

26. Carlson JT, Hedner JA, Elam M, Ejnell H, Sellgren J, Wallin BG. Augmented resting sympathetic activity in awake patients with obstructive sleep apnea. Chest 1993; 103: 1763-1768.

27. Hedner J, Ejnell H, Sellgren J, Hedner T, Wallin G. Is high and fluctuating muscle nerve sympathetic activity in the sleep apnea syndrome of pathogenetic importance for the development of hypertension? J Hypertens 1988; 6: S529-S531.

28. Somers VK, Mard AL, Abboud FM. Sympathetic activation by hypoxia and hypercapnia - implications for sleep apnea. Clin Exp Theory Pract 1988; A10, Suppl.1: 413-422.

29. Levinson PD, Millman RP. Causes and consequences of blood pressure alterations in obstructive sleep apnea. Arch Intern Med 1991; 151: 455-462.

30. Ostmann-Smith I. Cardiac sympathetic nerves as the final common pathway in induction of adaptive cardiac hypertrophy. Clin Sci 1981; 61: 265-272. 
